\title{
The Association between Dietary Diversity with Shift Work among the Nurses
}

\section{Khadijeh Mirzaei}

Department of Community Nutrition, School of Nutritional Sciences and Dietetics, Tehran University of Medical Sciences, Tehran, Iran

*Corresponding author: Khadijeh Mirzaei, Department of Community Nutrition, School of Nutritional Sciences and Dietetics, Tehran University of Medical Sciences, Tehran, Iran, Tel: +98-21-88955805; Fax: +98-21-88984861; E-mail: khmirzaeinut@gmail.com

Received date: Apr 22, 2018; Accepted date: Jun 05, 2018; Published date: Jun 12, 2018

Copyright: (c) 2018 Mirzaei K. This is an open-access article distributed under the terms of the Creative Commons Attribution License, which permits unrestricted use, distribution, and reproduction in any medium, provided the original author and source are credited.

\begin{abstract}
Background: Nutrition is related to different health problems. Working in shifts has been identified as one of the factors associated with overweight and obesity. This study was performed to assess the association between food intake and dietary diversity with shift work among nurses.
\end{abstract}

Methods: This cross-sectional study was conducted on 270 nurses working in hospitals under the supervision of Tehran University of Medical Sciences. A three-day 24-h food recall was used to evaluate food intake and diversity, Blood pressure $(\mathrm{mmhg})$, fasting blood glucose $(\mathrm{mg} / \mathrm{dl})$, insulin $(\mu \mathrm{m} / \mathrm{ml})$, lipid profile $(\mathrm{mg} / \mathrm{d})$, serum levels of cobalamin $(\mathrm{ng} / \mathrm{l})$, folic acid $(\mathrm{pg} / \mathrm{l})$ and anthropometric indices were also evaluated.

Results: Mean age of subjects was $35.01 \pm 6.52$ years. Mean dietary diversity scores (by Kant and IDDS methods) were $4.68 \pm 1.18$ and $5.77 \pm 1.25$, respectively. Among study participants the mean weight $(p<0.03)$, waist circumference $(p<0.02)$ and hip circumference $(p<0.001)$ showed a significant difference across the tertiles of Kant dietary diversity score. A significant difference was seen in terms of body mass index (BMI) and WHR $(p<0.03)$. This means that by increasing dietary diversity score, average height and weight reduces. It was also seen that by increasing the dietary diversity score, systolic blood pressure decreased and serum folic acid level increased, though these changes were statistically insignificant. In the Kant method, weight and hip circumference were increased in dietary diversity in the morning shift $(p=0.05)$. In the FAO method, insulin and vitamin B9 (Folic acid) levels decreased by increasing dietary diversity in the morning shift. However, the serum level of vitamins B9 (Folic acid) and B12 was increased by the increment of dietary diversity in the rotating shift.

Conclusion: Anthropometric factors are decreased by increasing the dietary diversity. It was also found that the mean of some anthropometric indices was higher in the morning shift. Higher dietary diversity and lower carbohydrate intake was also seen in the morning shift.

Keywords: Dietary diversity score; Food intake; Shift work; Nursing

\section{Introduction}

Nurses are the largest group of health care workers in organizations providing health services, and provide direct and indirect care services to patients [1]. Based on studies, factors such as lack of facilities, workload, lack of administrative support, dealing with patients or their relatives, and handling workplace violence are the most common stressors among those working in this occupation [2]. These stressors may affect nurses' dietary intakes. Disturbances in dietary intake are linked to several conditions such as obesity and overweight, high blood pressure, anemia, osteoporosis, diabetes, cancer and heart disease [3-5]. The relationship between diet and different disease has proven and so modifying people's diets can be considered as a factor for assessing and evaluating their health status [5].

According to studies, shift work is defined as work outside usual office time, and includes irregular, flexi-time, rotating and evening shifts [6]. The link between shift work and health problems is not clear, but issues with changes in sleep, as well as lifestyle and behavioral changes such as diet and smoking may be potential mediators in this regard [7].
In addition, work shifts have been identified as one of the factors associated with overweight and obesity. Research suggests that the overall risk of obesity and overweight may rise up to $39 \%$ in shift workers [8-11]. Also, a significant association has been proven between shifts and overweight and obesity in various studies [12]. Obesity is a risk factor for chronic diseases and is more common among shift workers (intermittent) than day workers [13-15]. Nurses' work plans may influence their health by increasing the risk of overweight and obesity [16].

Despite previous evidence that shift work may influence dietary intake and anthropometric measurements, there are few studies available investigating the associations of nurses' shift work with these variables. Therefore, this study aimed to assess the associations between food intake and food diversity as well as anthropometric measurements with shift work among the nurses affiliated to Tehran University hospitals. 


\section{Methods}

\section{Subjects}

This cross-sectional study was carried out with 270 nurses (246 females, 24 males) working in hospitals under the supervision of Tehran University. All personnel who graduated in the field of nursing from these hospitals were invited to participate in the study (Response rate $=80.2 \%)$. Then, the study participants were recruited based on certain inclusion criteria. The inclusion criteria included: Under 45 years old for men and under the menopausal age for women. Another factor was their willingness to cooperate in the study and complete it. Certain psychiatric disorders, such as mood disorders and depression, and endocrine disorders such as diabetes and thyroid diseases as well as other chronic disorders were exclusion criteria, as well as subjects who were taking any medication, and non-cooperation.

This study was approved by the Ethics-in-Research Commission of Endocrinology and Metabolism Research Institute, Tehran University of Medical Sciences (Ref Number: E-00172). Also, a full explanation of the purpose and process of the study was presented, along with the sampling methodology, and relevant parties were assured of the confidentiality of all information. Finally, a written informed consent was obtained from the subjects, and questionnaires were completed by an interviewer.

\section{Demographic characteristics}

Demographic information was collected using a questionnaire and researcher interviews. Also, participants' age, gender, education level, working schedules and other related information were recorded. Iranian nursing shifts were divided into these groups: morning fix, evening, night fix, evening and night, morning and evening, rotating.

\section{Anthropometric and blood pressure measurements}

Blood pressure was measured after 15 min of seated rest from the right arm using a digital monometer. After resting for another $5 \mathrm{~min}$, $\mathrm{BP}$ was measured again and the outcomes of these two measurements were recorded.

Anthropometric measurements such as weight, height, waist and hip circumference were recorded for all participants. Body weight was measured to the nearest $0.1 \mathrm{~kg}$ using a scale with subjects wearing light clothing (i.e. no sweaters, jackets, or belts) and no shoes. Height was measured to the nearest $0.5 \mathrm{~cm}$ using a Secastadiometer and with shoes removed. A plastic flexible tape was used to assess waist and hip circumferences to the nearest $0.5 \mathrm{~cm}$. Waist measurement was assessed at half the distance between the bottom of the xiphoid process and the umbilicus, and the hip measurement was taken at the largest anterior protrusion. The ratio between waist and hip (WHR) was computed. Body mass index (BMI) was calculated from the height and weight data; $\mathrm{BMI}=\mathrm{kg} / \mathrm{m}^{2}$.

\section{Food intake and food diversity}

A three-day 24-h food recall (2 working days and a holiday) was used to evaluate food intake and diversity. Then the food intake data were analyzed by Nutritionist [4]. Food diversity assessment was performed using the 2 suggested methods of the FAO (Food and Agriculture Organization) and Kant.
FAO [17] method proposes 9 food groups for evaluating individual dietary diversity score (IDDS), which is on a 0-9 scale. In this study, a score of 1 was allocated for the consumption of at least half a serving of each food group per day, while zero points were allocated for consumption lower than that. Finally, the scores obtained by these 9 groups are added together to provide the overall IDDS score. These 9 groups included: starchy foods, dark green leafy vegetables, fruits and vegetables rich in vitamin $A$, fruits and other vegetables, organ meats, fish, eggs, beans, seeds and nuts, and milk/dairy products.

In Kant's method [18], foods are first categorized to 5 main groups of grains, vegetables, fruits, meat and dairy products. Then the main groups are converted into 23 subgroups to provide the dietary diversity score among the groups in the food pyramid [19]. Groups were divided as listed below:

Cereals had 7 subgroups covering white bread, whole bread, wholegrain biscuits, cooked rice, cooked pasta, flour and breakfast cereals. Vegetables had 7 subgroups of vegetables, potatoes, tomatoes and its products, other starchy vegetables, legumes, yellow and orange vegetables, and green vegetables. Fruits were divided into 2 groups of citrus fruits and berries, other fruits and juices. Dairy products contained 3 subgroups: milk, yogurt and cheese \& curd. Meats were divided into 4 subgroups of red meat, fish, poultry and eggs. The maximum dietary diversity score awarded to each of the five groups is 2 and ultimately, the sum of these numbers is calculated as the total score. As a result, dietary diversity score ranged from 0 to 10 .

\section{Biochemical assessment}

$12 \mathrm{cc}$ fasting venous blood samples were collected after 8-12 h fasting in sterile condition. All blood samples were collected between 8:00 to 10:00 AM. Serums were centrifuged and stored at $-40^{\circ} \mathrm{C}$. Serum folic acid and cobalamin were measured by radio immune assay (RIA) and DRG diagnostic kit.

The Glucose Oxidase Phenol 4-Aminoantipyrine Peroxidase (GOD/ PAP) method was used to measure fasting blood glucose level. The methods of Glycerol-3-phosphate oxidase Phenol 4-Aminoantipyrine Peroxidase (GPO-PAP), Enzymatic Endpoint and enzymatic clearance were used to measure serum triglycerides, total cholesterol and LDL \& HDL, respectively. Fasting blood glucose and lipid profile measurements were carried out by Randox laboratory kit (Hitachi 902). Serum insulin level was determined by enzyme-linked immunesorbent assay (Human insulin ELISA kit, DRG Pharmaceuticals, $\mathrm{GmbH}$, Germany). The minimum detectable concentration level was $1.76 \mu \mathrm{lU} / \mathrm{ml}$, Intra CV was $2.19 \%$ and Inter CV was $4.4 \%$.

\section{Statistical Analysis}

Statistical analysis was performed using the Statistical Package for Social Sciences (SPSS version 20.0). At first the normality of the variables were examined by the Kolmogorov-Smirnov test. FAO \& Kant criteria were used in order to determine dietary diversity score (DDS). To evaluate the relationship between quantitative variables by tertiles of dietary diversity, and also in order to evaluate the dietary intake in grouped shifts, the ANOVA test (one-way analysis of variance) was used. To eliminate the effects of age, sex, and energy, ANCOVA was used. The chi-square test was used to evaluate differences between qualitative variables. To determine the association between dietary diversity in different grouped shifts and demographic and anthropometric and biochemical variables, correlations tests were used. A significance level of 0.05 was determined for all statistical tests. 
Citation: Mirzaei K (2018) The Association between Dietary Diversity with Shift Work among the Nurses. J Nurs Care 7: 461. doi:

Page 3 of 8

The P-value was calculated using one-way analysis of variance. Posthoc test was used in order to perform pairwise comparison of dietary diversity tertiles. Similar letters indicate significant differences $(\mathrm{p}$ $<0.05)$ between the two tertiles.

\section{Results}

\section{Anthropometric, food intake and food diversity}

The baseline characteristics of participants across categories of DDS (Dietary Diversity Scores) were calculated by the Kant and FAO methods, and are shown in Table 1. The mean age of subjects was 35.01 \pm 6.52 years. The mean range of dietary diversity score by Kant and IDDS method was $4.68 \pm 1.18$ and $5.77 \pm 1.25$, respectively.

\begin{tabular}{|c|c|c|c|c|c|c|c|c|c|c|}
\hline & KANT & & & $\mathrm{P}$ & $P^{*}$ & FAO & & & $\mathrm{P}$ & $\mathrm{P}^{*}$ \\
\hline & $\mathrm{T} 1(\mathrm{n}=93)$ & T2 (n=87) & T3 $(n=90)$ & & & $\mathrm{T} 1(n=104)$ & T2 $(n=82)$ & T3 $(n=84)$ & & \\
\hline & Mean \pm SD & Mean \pm SD & Mean \pm SD & & & Mean \pm SD & Mean \pm SD & Mean \pm SD & & \\
\hline Age (year) & $35.59 \pm 6.28$ & $34.09 \pm 6.57$ & $35.49 \pm 6.63$ & 0.24 & 0.932 & $35.79 \pm 6.58$ & $35.05 \pm 6.09$ & $34.31 \pm 6.78$ & 0.31 & 0.132 \\
\hline Height $(\mathrm{cm})$ & $161.72 \pm 7.01$ & $160.98 \pm 8.59$ & $161.58 \pm 7.71$ & 0.79 & 0.1 & $162.55 \pm 7.29 c$ & $161.48 \pm 8.33$ & $160.05 \pm 7.57 c$ & 0.09 & $<0.001^{*}$ \\
\hline Weight (kg) & $68.70 \pm 12.76 a$ & $63.92 \pm 10.00 a$ & $66.39 \pm 12.51$ & $0.03^{*}$ & $0.01^{*}$ & $68.08 \pm 13.28$ & $65.49 \pm 10.07$ & $65.27 \pm 11.94$ & 0.2 & $0.02^{*}$ \\
\hline Waist (cm) & $78.75 \pm 10.44 a$ & $74.65 \pm 8.84 a, b$ & $77.81 \pm 11.15 b$ & $0.02^{*}$ & 0.14 & $78.46 \pm 10.85$ & $75.72 \pm 9.02$ & $76.93 \pm 10.77$ & 0.19 & 0.17 \\
\hline Hip (cm) & $97.41 \pm 10.41 a$ & $92.96 \pm 8.74 a, b$ & $93.56 \pm 9.88 b$ & $<0.001^{*}$ & $0.04^{*}$ & $95.94 \pm 10.45$ & $93.81 \pm 8.38$ & $94.04 \pm 10.47$ & 0.27 & 0.18 \\
\hline Shift Work (\%) & & & & $0.44^{*}$ & - & & & & $0.41^{*}$ & \\
\hline Morning & 32.6 & 36.1 & 41.6 & & & 37.6 & 43.8 & 28.9 & & \\
\hline Evening & 3.3 & 6 & 1.1 & & & 3 & 1.3 & 6 & & \\
\hline Night & 15.2 & 19.3 & 14.6 & & & 16.8 & 20 & 12 & & \\
\hline Rotation & 38 & 33.7 & 33.7 & & & 35.6 & 30 & 39.8 & & \\
\hline Evening \& Night & 8.7 & 4.8 & 9 & & & 6.9 & 2.5 & 13.3 & & \\
\hline $\begin{array}{l}\text { Morning } \\
\text { Rotation }\end{array}$ & 2.2 & 0 & 0 & & & 0 & 2.5 & 0 & & \\
\hline BP sistol (mmhg) & $109.43 \pm 12.89$ & $108.76 \pm 13.03$ & $109.26 \pm 12.85$ & 0.94 & 0.72 & $109.48 \pm 13.31$ & $109.04 \pm 12.80$ & $108.90 \pm 12.53$ & 0.95 & 0.97 \\
\hline BP diastol(mmhg) & $70.18 \pm 10.58$ & $69.99 \pm 10.6$ & $71.14 \pm 10.42$ & 0.73 & 0.66 & $70.28 \pm 10.35$ & $69.56 \pm 10.61$ & $71.49 \pm 10.11$ & 0.49 & 0.39 \\
\hline $\mathrm{FBS}(\mathrm{mg} / \mathrm{dl})$ & $87.74 \pm 17.86$ & $89.08 \pm 23.94$ & $85.42 \pm 13.06$ & 0.42 & 0.51 & $89.71 \pm 24.42 a$ & $84.31 \pm 13.64 a$ & $87.51 \pm 13.85$ & 0.15 & 0.48 \\
\hline LDL (mg/dl) & $92.31 \pm 22.16$ & $91.80 \pm 21.80$ & $96.84 \pm 24.23$ & 0.26 & 0.11 & $92.53 \pm 24.01$ & $92.84 \pm 18.97$ & $95.93 \pm 24.74$ & 0.55 & 0.21 \\
\hline $\mathrm{HDL}(\mathrm{mg} / \mathrm{dl})$ & $53.39 \pm 13.19$ & $53.98 \pm 12.52$ & $52.72 \pm 12.38$ & 0.81 & 0.72 & $53.24 \pm 11.92$ & $52.54 \pm 13.41$ & $54.27 \pm 12.93$ & 0.68 & 0.41 \\
\hline TG (mg/dl) & $102.28 \pm 59.99$ & $109.60 \pm 74.61$ & $118.70 \pm 84.18$ & 0.31 & 0.27 & $107.46 \pm 80.23$ & $113.63 \pm 70.19$ & $109.96 \pm 68.49$ & 0.85 & 0.96 \\
\hline Cholesterol(mg/dl) & $172.34 \pm 33.34$ & $174.20 \pm 33.50$ & $178.94 \pm 34.23$ & 0.39 & 0.12 & $172.55 \pm 35.25$ & $173.65 \pm 28.24$ & $179.83 \pm 36.40$ & 0.3 & 0.09 \\
\hline Insulin ( $\mu \mathrm{g} / \mathrm{ml})$ & $11.95 \pm 12.20$ & $12.83 \pm 14.23$ & $11.23 \pm 7.36$ & 0.6 & 0.51 & $12.12 \pm 11.80$ & $12.20 \pm 12.83$ & $11.61 \pm 9.86$ & 0.93 & 0.99 \\
\hline Folic acid (pg/l) & $6.67 \pm 8.04$ & $6.75 \pm 8.25$ & $8.84 \pm 11.83$ & 0.24 & 0.07 & $8.37 \pm 9.83$ & $5.65 \pm 6.64$ & $7.97 \pm 11.37$ & 0.14 & 0.87 \\
\hline B12 (ng/l) & $\begin{array}{ll}329.13 & \pm \\
172.45 & \end{array}$ & $\begin{array}{l}324.30 \\
145.39\end{array}$ & $\begin{array}{ll}351.30 \\
157.06\end{array} \quad \quad \pm$ & 0.5 & 0.19 & $\begin{array}{ll}335.32 \\
163.30\end{array}$ & $\begin{array}{ll}321.66 \\
150.73\end{array}$ & $\begin{array}{ll}348.39 & \pm \\
162.76 & \end{array}$ & 0.58 & 0.49 \\
\hline BMI (kg/m2) & $26.21 \pm 4.31 \mathrm{a}$ & $24.66 \pm 3.38 a$ & $25.34 \pm 3.88$ & $0.03^{*}$ & 0.08 & $25.71 \pm 4.41$ & $25.10 \pm 3.33$ & $25.41 \pm 3.87$ & 0.58 & 0.66 \\
\hline WHR & $0.80 \pm 0.07 c$ & $0.80 \pm 0.06 b$ & $0.83 \pm 0.09 c, b$ & $0.03^{*}$ & 0.23 & $0.81 \pm 0.07$ & $0.80 \pm 0.06$ & $0.82 \pm 0.09$ & 0.5 & 0.88 \\
\hline
\end{tabular}


Citation: Mirzaei K (2018) The Association between Dietary Diversity with Shift Work among the Nurses. J Nurs Care 7: 461. doi:

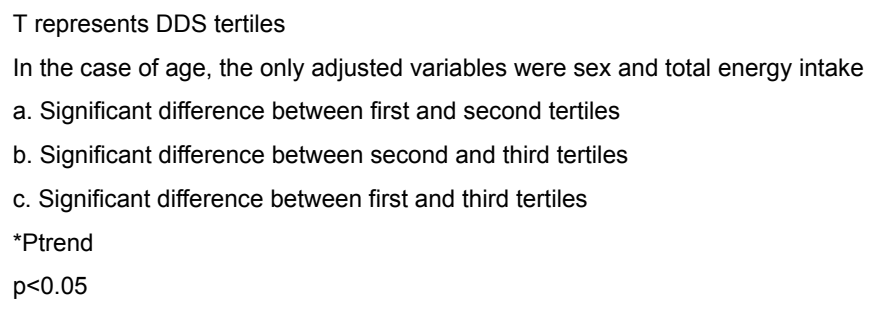

Table 1: Baseline characteristics across tertiles of dietary diversity score using KANT and FAO methods.

Mean weight, waist circumference and hip circumference showed a significant difference with dietary diversity score in Kant tertiles $(\mathrm{p}<0.03, \mathrm{p}<0.02, \mathrm{p}<0.001$; respectively). Also, weight and hip circumference retained a significant difference after adjusting for age, gender and energy. Additionally, a significant relationship was seen in terms of body mass index and waist to hip ratio $(p<0.03)$. Waist to hip ratio increased by increments in dietary diversity. However, after adjusting for age, gender and energy variables, this effect disappeared. After comparing variables through the post-hoc test, the mean weight, WC, WHR and BMI significantly decreased by increasing the food diversity from first tertile to the second. A significant relationship was observed in terms of WHR between the first and third tertiles, and also between the second and third tertiles. Both of which indicate that the mean WHR is increased with dietary diversity increment.

A significant difference was seen in terms of mean height $(\mathrm{p}<0.001)$ and weight $(\mathrm{p}<0.02)$ after adjusting for age, gender and energy in FAO tertiles. This means that by increasing dietary diversity score, the average of height and weight was reduced. It was also seen that by increasing the dietary diversity score, systolic blood pressure decreased and serum folic acid level increased, but none of these changes were statistically significant.

\section{Relationships between other study variables}

The mean and standard deviation of variables of different shifts is shown in Table 2. The mean age, weight, waist and hip circumference, HDL and insulin level and BMI were higher in the morning shift than in other shifts. Also, a significant relationship was seen between age $(p<0.00)$ across different shifts, which remained significant even after adjusting for gender and energy $(\mathrm{p}<0.00)$.

\begin{tabular}{|c|c|c|c|c|c|c|}
\hline & \multicolumn{4}{|l|}{ Shiftcat3 } & $\mathbf{P}$ & $\mathbf{P}^{*}$ \\
\hline & T1 & T2 & \multicolumn{2}{|l|}{ T3 } & \multirow[b]{3}{*}{$<0.001$} & \multirow[b]{3}{*}{$<{ }_{*}^{<} 0.0012$} \\
\hline & Mean \pm SD & Mean \pm SD & \multicolumn{2}{|l|}{ Mean \pm SD } & & \\
\hline Age (year) & $\begin{array}{ll}38.57 & \pm \\
6.20^{\mathrm{a}, \mathrm{b}} & \end{array}$ & $\begin{array}{l}33.61 \\
5.84^{a}\end{array}$ & $\begin{array}{l}32.57 \\
5.79^{b}\end{array}$ & \pm & & \\
\hline Height (cm) & $\begin{array}{l}161.60 \\
7.53\end{array}$ & $\begin{array}{l}160.35= \\
7.96\end{array}$ & $\begin{array}{l}162.15 \\
7.75\end{array}$ & & 0.31 & 0.47 \\
\hline Weight (kg) & $\begin{array}{l}67.61 \\
11.27\end{array}$ & $\begin{array}{l}65.58 \\
12.61\end{array}$ & $\begin{array}{l}65.09 \\
11.64\end{array}$ & & 0.29 & 0.42 \\
\hline Waist (cm) & $\begin{array}{l}78.84 \\
10.99^{c}\end{array}$ & $\begin{array}{l}76.21 \\
10.26\end{array}$ & $\begin{array}{l}75.46 \\
8.84^{\mathrm{c}}\end{array}$ & \pm & 0.05 & 0.4 \\
\hline Hip (cm) & $\begin{array}{l}95.45 \\
10.68\end{array}$ & $\begin{array}{l}94.62 \quad \pm \\
8.85\end{array}$ & $\begin{array}{l}93.52 \\
9.32\end{array}$ & & 0.38 & 0.62 \\
\hline
\end{tabular}

\begin{tabular}{|c|c|c|c|c|c|}
\hline $\begin{array}{l}\text { BPsistol } \\
\text { (mmhg) }\end{array}$ & $\begin{array}{ll}109.68 & \pm \\
12.05 & \end{array}$ & $\begin{array}{ll}107.17 & \pm \\
12.23 & \end{array}$ & $\begin{array}{ll}110.07 & \pm \\
13.87 & \end{array}$ & 0.3 & 0.08 \\
\hline $\begin{array}{l}\text { BPdiastol } \\
\text { (mmhg) }\end{array}$ & $70.02 \pm 9.67$ & $\begin{array}{ll}69.34 & \mathbf{I} \\
10.22 & \end{array}$ & $\begin{array}{l}71.49 \\
10.88\end{array}$ & 0.38 & $0.02^{*}$ \\
\hline FBS (mg/dl) & $\begin{array}{ll}90.38 & \pm \\
22.77^{a} & \end{array}$ & $\begin{array}{ll}83.65 & \pm \\
10.29^{a} & \end{array}$ & $\begin{array}{l}85.99 \\
17.52\end{array}$ & 0.05 & 0.28 \\
\hline LDL (mg/dl) & $\begin{array}{l}95.04 \\
24.39\end{array}$ & $\begin{array}{ll}90.24 & \pm \\
21.67 & \end{array}$ & $\begin{array}{l}94.17 \\
22.00\end{array}$ & 0.37 & 0.26 \\
\hline $\mathrm{HDL}(\mathrm{mg} / \mathrm{dl})$ & $\begin{array}{l}54.34 \\
12.70\end{array}$ & $\begin{array}{ll}53.80 \\
13.44\end{array}$ & $\begin{array}{l}52.23 \\
11.67\end{array}$ & 0.48 & 0.3 \\
\hline TG (mg/dl) & $\begin{array}{ll}110.19 & \pm \\
67.76 & \end{array}$ & $\begin{array}{l}110.86 \\
85.70\end{array}$ & $\begin{array}{l}106.66 \\
65.93\end{array}$ & 0.91 & 0.73 \\
\hline $\begin{array}{l}\text { Cholesterol } \\
(\mathrm{mg} / \mathrm{dl})\end{array}$ & $\begin{array}{ll}178.27 & \pm \\
34.51 & \end{array}$ & $\begin{array}{l}171.59 \quad \pm \\
33.28\end{array}$ & $\begin{array}{ll}173.81 & \pm \\
32.77 & \end{array}$ & 0.41 & 0.66 \\
\hline Insulin $(\mu \mathrm{g} / \mathrm{ml})$ & $\begin{array}{ll}12.07 & \pm \\
10.26 & \end{array}$ & $\begin{array}{ll}11.29 & \pm \\
9.84 & \end{array}$ & $\begin{array}{l}11.03 \\
9.35\end{array}$ & 0.75 & 0.96 \\
\hline Folic acid (pg/l) & $8.65 \pm 9.78$ & $6.27 \pm 6.86$ & $\begin{array}{ll}7.29 & \pm \\
10.88 & \end{array}$ & 0.28 & 0.58 \\
\hline B12 (ng/l) & $\begin{array}{l}368.51 \\
174.42^{\mathrm{a}, \mathrm{c}}\end{array}$ & $\begin{array}{l}298.49 \\
153.42^{\mathrm{a}}\end{array}$ & $\begin{array}{ll}320.33 & \pm \\
130.46^{c} & \end{array}$ & 0.01 & 0.12 \\
\hline BMI $\left(\mathrm{kg} / \mathrm{m}^{2}\right)$ & $25.86 \pm 3.80^{c}$ & $\begin{array}{ll}25.45 & \pm \\
4.20 & \end{array}$ & $\begin{array}{ll}24.68 & \pm \\
3.50^{\mathrm{C}} & \end{array}$ & 0.09 & 0.66 \\
\hline WHR & $0.82 \pm 0.09$ & $0.80 \pm 0.07$ & $0.81 \pm 0.08$ & 0.1 & 0.08 \\
\hline \multicolumn{6}{|c|}{$\begin{array}{l}\mathrm{P}^{*} \text { represents ANCOVA assessment after adjusting for age, sex and energy } \\
\mathrm{T}(\mathrm{T} 1=\text { =morning fix, } \mathrm{T} 2=\text { =evening, night, evening-night fix, T3=rotation, mor } \\
\text { and rotation) }\end{array}$} \\
\hline $\begin{array}{l}\text { In the case of ag } \\
\text { a. Significant dif } \\
\text { b. Significant dif } \\
\text { c. Significant diff } \\
p<0.05\end{array}$ & $\begin{array}{l}\text {, the only adjus } \\
\text { rence between } \\
\text { rence between between }\end{array}$ & $\begin{array}{l}\text { ted variables } \\
\text { first and secor } \\
\text { second and th } \\
\text { first and third }\end{array}$ & $\begin{array}{l}\text { were sex and e } \\
\text { nd tertiles } \\
\text { iird tertiles } \\
\text { tertiles }\end{array}$ & nergy & \\
\hline
\end{tabular}

Table 2: Mean \pm SD of studied variables based on divided shifts.

Fasting blood glucose was significantly higher in the morning working group than the night working group. Morning shift nurses also had a significantly higher BMI than rotating shift nurses.

The mean and standard deviations of food intake across various shifts is shown in Table 3. A significant relationship was observed between carbohydrate intake $(\mathrm{p}<0.001)$, lipids $(\mathrm{p}<0.01)$ and PUFA $(\mathrm{p}<0.01)$. Protein intake was lower in morning shift nurses than night 
Citation: Mirzaei K (2018) The Association between Dietary Diversity with Shift Work among the Nurses. J Nurs Care 7: 461. doi:

Page 5 of 8

or rotating shift nurses, but this difference was not statistically significant.

\begin{tabular}{|c|c|c|c|c|c|}
\hline & \multicolumn{3}{|l|}{ Shiftcat3 } & $\mathbf{P}$ & $\mathbf{P}^{*}$ \\
\hline & $\mathrm{T1}$ & T2 & T3 & & \\
\hline & Mean \pm SD & Mean \pm SD & Mean \pm SD & & \\
\hline Carbohydrate (g) & $2.63 \pm 3.94^{c}$ & $2.68 \pm 4.52^{b}$ & $2.49 \pm 4.14^{\mathrm{c}, \mathrm{b}}$ & $<0.001^{*}$ & 0.05 \\
\hline Fat $(g)$ & $7.06 \pm 1.75^{\mathrm{c}}$ & $6.74 \pm 1.95^{\mathrm{b}}$ & $7.57 \pm 1.75^{\mathrm{c}, \mathrm{b}}$ & $0.01^{*}$ & 0.15 \\
\hline Protein (g) & $5.84 \pm 1.35$ & $6.11 \pm 1.68$ & $6.12 \pm 1.74$ & 0.39 & 0.13 \\
\hline SFA (g) & $1.75 \pm 5.09$ & $1.83 \pm 8.88$ & $1.85 \pm 5.90$ & 0.56 & 0.31 \\
\hline PUFA (g) & $1.78 \pm 7.96$ & $1.58 \pm 7.30^{b}$ & $1.96 \pm 8.39^{b}$ & $0.01^{*}$ & 0.28 \\
\hline Linolenic acid (g) & $2.80 \pm 4.02$ & $2.95 \pm 5.06$ & $3.40 \pm 5.20$ & 0.65 & 0.25 \\
\hline $\operatorname{EPA}(\mathrm{g})$ & $0.01 \pm 0.04$ & $0.01 \pm 0.06$ & $0.01 \pm 0.06$ & 0.82 & 0.36 \\
\hline Vitamin $\mathrm{A}(\mu \mathrm{g})$ & $8.40 \pm 9.61$ & $7.79 \pm 5.91$ & $8.68 \pm 1.17$ & 0.83 & 0.72 \\
\hline Zinc (mg) & $8.50 \pm 2.23$ & $8.68 \pm 2.23$ & $8.60 \pm 2.18$ & 0.86 & 0.38 \\
\hline Vitamin E (mg) & $1.89 \pm 8.86$ & $1.63 \pm 7.43^{\mathrm{b}}$ & $2.04 \pm 8.69^{b}$ & $<0.001$ & 0.54 \\
\hline Folate $(\mu \mathrm{g})$ & $3.11 \pm 1.10$ & $3.18 \pm 9.76$ & $3.18 \pm 1.27$ & 0.9 & 0.79 \\
\hline Folic acid (g) & $2.58 \pm 8.58$ & $2.41 \pm 9.19^{b}$ & $2.72 \pm 8.69^{b}$ & 0.07 & 0.61 \\
\hline
\end{tabular}

\begin{tabular}{|l|l|l|l|l|l|}
\hline Linoleic acid $(\mathrm{g})$ & $7.99 \pm 2.67$ & $1.04 \pm 3.46$ & $1.10 \pm 3.46$ & 0.78 & 0.33 \\
\hline Calcium $(\mathrm{mg})$ & $1.32 \pm 3.32$ & $1.39 \pm 3.20$ & $1.36 \pm 2.83$ & 0.35 & 0.25 \\
\hline Vitamin D (IU) & $5.31 \pm 1.23$ & $5.79 \pm 1.76$ & $4.43 \pm 1.11$ & 0.8 & 0.79 \\
\hline DHA (g) & $0.03 \pm 0.13$ & $0.05 \pm 0.17$ & $0.04 \pm 0.16$ & 0.8 & 0.33 \\
\hline
\end{tabular}

$\mathrm{P}^{*}$ represents ANCOVA assessment after adjusting for age, sex and energy

$T$ (T1=morning fix, T2=evening, night, evening-night fix, T3=rotation, morning and rotation)

In the case of age, the only adjusted variables were sex and energy

b. Significant difference between second and third tertiles

c. Significant difference between first and third tertiles $p<0.05$

Table 3: Mean \pm SD of dietary intakes based on divided shifts.

The work shifts were divided into 3 groups, and the relationship between dietary diversity and these shifts is presented in Table 4 . In the Kant method, weight and hip circumference were increased along with increases in dietary diversity in the morning shift $(\mathrm{p}=0.05)$. In the FAO method, insulin and B9 (Folic Acid) level were decreased by increasing dietary diversity in morning shift. However, the serum level of B9 (Folic Acid) and B12 was increased by the increment of dietary diversity in the rotating shift group.

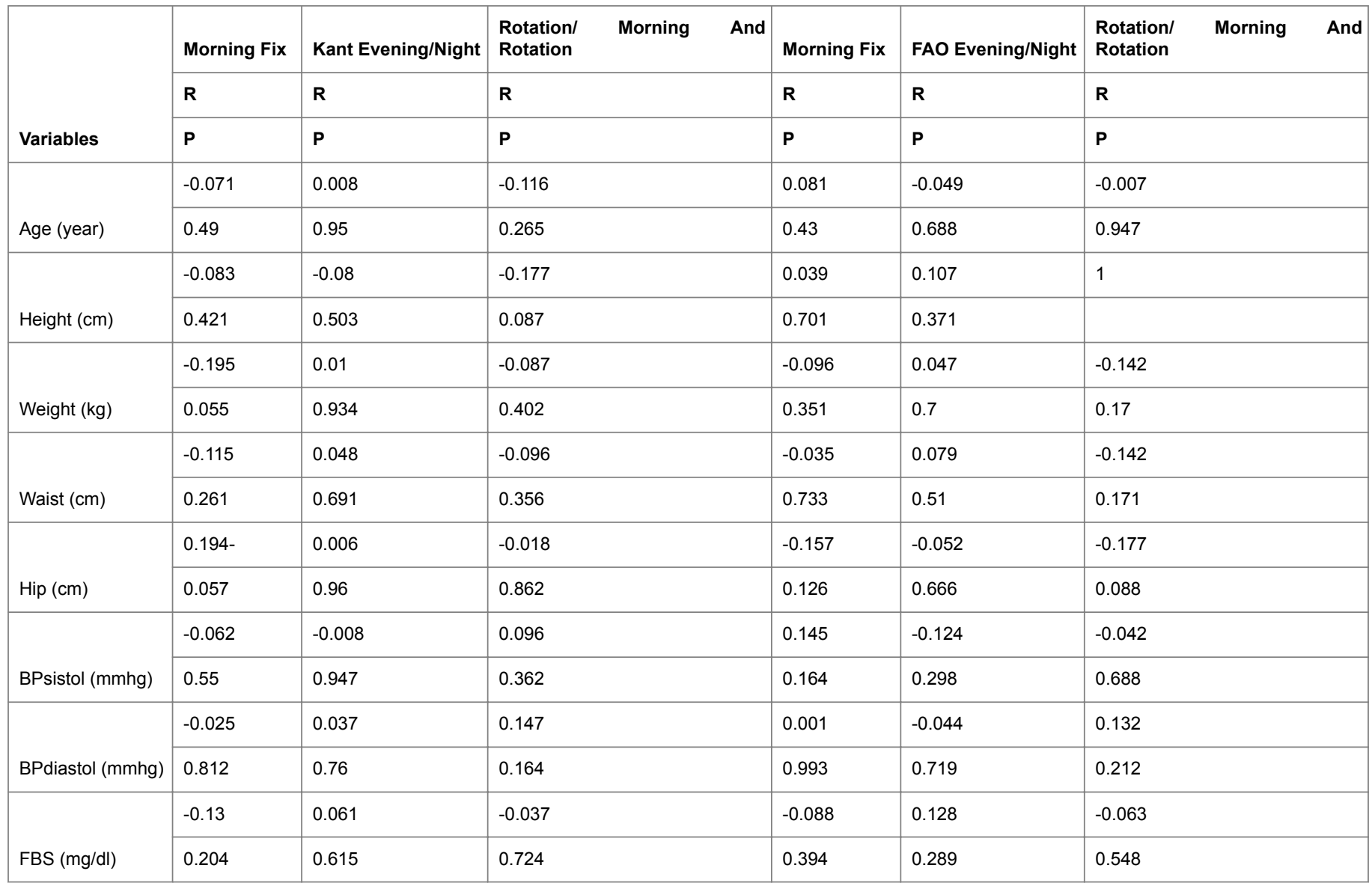


Citation: Mirzaei K (2018) The Association between Dietary Diversity with Shift Work among the Nurses. J Nurs Care 7: 461. doi:

Page 6 of 8

\begin{tabular}{|c|c|c|c|c|c|c|}
\hline \multirow[b]{2}{*}{ LDL (mg/dl) } & 0.102 & 0.003 & 0.095 & 0.087 & 0.002 & 0.165 \\
\hline & 0.319 & 0.98 & 0.361 & 0.399 & 0.99 & 0.112 \\
\hline \multirow[b]{2}{*}{ HDL (mg/dl) } & 0.04 & -0.112 & 0.208 & 0.075 & -0.177 & 0.189 \\
\hline & 0.697 & 0.352 & 0.044 & 0.464 & 0.14 & 0.068 \\
\hline \multirow[b]{2}{*}{ TG (mg/dl) } & 0.055 & 0.062 & -0.083 & 0.077 & 0.221 & -0.104 \\
\hline & 0.59 & 0.61 & 0.425 & 0.451 & 0.064 & 0.318 \\
\hline \multirow[b]{2}{*}{ Cholesterol } & 0.176 & -0.031 & 0.12 & 0.132 & -0.004 & 0.172 \\
\hline & 0.084 & 0.796 & 0.251 & 0.198 & 0.97 & 0.096 \\
\hline \multirow[b]{2}{*}{ Insulin ( $\mu \mathrm{g} / \mathrm{ml})$} & -0.025 & 0.182 & -0.221 & -0.089 & 0.056 & -0.13 \\
\hline & 0.808 & 0.128 & 0.032 & 0.038 & 0.641 & 0.21 \\
\hline \multirow[b]{2}{*}{ Folic acid (pg/l) } & -0.12 & -0.151 & 0.113 & -0.19 & 0.108 & 0.248 \\
\hline & 0.253 & 0.221 & 0.282 & 0.068 & 0.382 & 0.017 \\
\hline \multirow[b]{2}{*}{ B12 (ng/l) } & 0.09 & -0.037 & 0.196 & 0.007 & -0.02 & 0.257 \\
\hline & 0.392 & 0.764 & 0.061 & 0.947 & 0.869 & 0.013 \\
\hline \multirow[b]{2}{*}{ BMI (kg/m2) } & -0.123 & -0.024 & -0.138 & -0.172 & 0.079 & $<0.001$ \\
\hline & 0.229 & 0.844 & 0.182 & 0.092 & 0.511 & 0.999 \\
\hline \multirow[b]{2}{*}{ WHR } & 0.129 & 0.135 & 0.004 & 0.07 & 0.033 & -0.137 \\
\hline & 0.209 & 0.258 & 0.966 & 0.498 & 0.783 & 0.188 \\
\hline
\end{tabular}

Table 4: The relationship between dietary diversity in different shifts and with different variables.

\section{Discussion}

In the current study, it was shown that by increasing dietary diversity, mean weight, waist circumference, hip circumference and body mass index scores were reduced, while the waist to hip ratio increases. Many similar studies have also confirmed these findings. For example, in a study by Mirmiran et al. [20], those who were in the first quartile of DDS had higher levels in some anthropometric factors. No significant difference was seen in their study between DDS quartiles by BMI and WC. However, waist to hip ratio was higher in the first quartile compared to the fourth quartile which indicates higher abdominal obesity in people who have less food diversity. Azadbakht et al. [21] showed a reduction in the possibility of obesity by increasing DDS. A significant difference was also observed in terms of mean BMI, WC and WHR in DDS quartiles. However, the results are contradictory on this issue as well. McCrory and his colleagues observed an increase in obesity due to DDS increasing [22]. The people with obesity and abdominal obesity had highest level of DDS than non-obese individuals in a study by Jayawardena et al. [23]. Increasing obesity levels in parallel with increasing dietary diversity could be due to increased appetite and consequent increased energy intake [24,25]. Several studies have shown a relationship between increased energy intake and increased dietary diversity [26,27]. Dietary diversity can act as a double-edged sword for energy regulation, and may have positive or negative effects on obesity, based on which food groups increase dietary diversity [22]. In addition, the present study's results demonstrated that DDS, as calculated by the Kant method, was more strongly associated with anthropometric measures, including indices of central obesity like WC. Moreover, DDS calculated in that way was also associated with serum concentrations of insulin. This is in line with previous studies which found a significant association of central obesity with insulin resistance [8-11].

The present results also demonstrated a higher level of mean age, weight, waist and hip circumference, BMI, HDL and glucose in the morning shift. In this regard, the results are different. There was an inversely significant relationship between waist and hip circumference with increased dietary diversity in morning shift nurses.

The average intake of carbohydrates and age was higher in night and evening shift nurses. Unhealthy and irregular food plans, such as skipping breakfast, may cause weight changes. Work shifts are one of the causes for disturbed normal diets and unhealthy food choices [28-30]. Several studies have proven the relationship between shifts and overweight and obesity [11,31]. In a study of Korean nurses, it was found that rotating shift workers were younger. This study is in line with the current study, since younger people are more likely to be involved and active in night and rotating shifts. Also, those with longer shifts were older and had higher BMI and BP [32].

In a Malaysian study on women working in an electronic equipment factory, a significant relationship was observed between overweight workers and working in the night shift [11]. Long shifts were a predictor of increased BMI in a cross-sectional study [33]. In an Australian cross-sectional study, it was shown that nurses working shifts had a 1.15-times greater risk of obesity and overweight, while only fixed night shifts were linked to obesity $[34,35]$. 
Page 7 of 8

Western studies have also shown high rates of obesity among night shift nurses $[33,36]$. In another study it was indicated that night shift workers had higher BMI than day shift workers [37].

In a Sudo et al. [38] study, total energy intake in night shift workers was less than in the day shift. This was due to the low frequency of meals and low-quality foods at night. Rotating schedules with night shifts may be a reason for lower weights in these nurses [39]. Job stress is also higher in rotating shifts [40]. In some studies, it was shown that nurses may miss opportunities to snack during the day due to their heavy workloads. Night shift nurses may also consume unhealthy snacks in the middle of the night $[29,30,41]$.

Another study found that cookies and snacks consumption through the shift was higher than other healthy choices [42]. This may be due to differences in working hin several countries. Korean and American nurses work 8 and $12 \mathrm{~h}$, respectively [32,43]. It is different for Iranian nurses, who work $6 \mathrm{~h}$ in morning shifts and $12 \mathrm{~h}$ in night shifts. In general, nurses may enjoy better health due to higher levels of health education and self-care than the public $[44,45]$. Lower and higher blood pressure levels were observed in morning and night shifts, respectively [32].

It should be noted that nurses are among the most important members of a health care management process. More health care managers will manage health care processes better for a range of different patients. This will lead to increased patient health knowledge, self-management skills, and readiness to make changes in health behaviors [46]. Adherence to a better dietary approach is recommended for nurses in night or evening shifts, as well as those in rotations which involve night shifts.

\section{Strengths and Limitations:}

According to the literature search, no study exists evaluating the relationship between dietary diversity and dietary intake with nurses' shifts; this was one of the strengths of this study. In addition, two different methods for evaluation were used for evaluating dietary diversity score, each of which had its own pros and cons.

One of the limitations of this study was its cross-sectional nature, which has little ability to detect causality. In addition, the effect of different variables cannot be investigated over time. Other limitations include non-evaluation of economic status, which can affect people's stress levels, as well as their access to food. The majority of study participants were females. Further studies on both sexes are needed to determine the influence of gender differences on these findings. In addition, other nutritional data was not collected. It has been seen that nutraceuticals induce additional health benefits [47]. Furthermore, due to the limited sample size, it was not possible to perform multivariate regression analysis. Finally, data was not collected on participants' physical activity in this study, which is an important confounder.

\section{Conclusion}

In the current study, it was found that anthropometric factors such as weight, waist and hip circumference and BMI are decreased by increases in dietary diversity. While waist to hip ratio increased, it was also found that the mean age, weight, waist and hip circumference and body mass index was higher in the morning shift. Also, it was revealed that the average intake of carbohydrates was higher during night and evening shifts.

\section{Acknowledgments}

We would like to thank the international campus of Tehran University of Medical Sciences and the Institute of Endocrinology and Metabolism at Tehran University of Medical Sciences, as well as all partners who helped to implement this project.

\section{References}

1. Zarea K, Negarandeh R, Dehghan-NAyeri, N, Rezaei-Adaryani M (2009) Nursing staff shortages and job satisfaction in Iran: Issues and challenges. Nurs Health Sci 11: 326-331.

2. Gholamzadeh S, Sharif F, Rad FD (2011) Sources of occupational stress and coping strategies among nurses who are working in admission and emergency department in hospitals affiliated to Shiraz University of Medical Sciences, Iran. Iran J Nurs Midwifery Res 16: 41-46.

3. Ahmadi SM, Eftekhari MH, Firoozabadi A, Keshavarzi S (2012) Assessment of serum leptin and thyroid hormone levels among depressed women. Shiraz E Med J 13: 169-78.

4. Mahan LK, Raymond JL, Escott-Stump S (2017) Krause's food and the nutrition care process. Elsevier.

5. Bano KA, Batool A (2007) Metabolic syndrome, cardiovascular disease and type diabetes. J Pak Med Assoc 57: 511-515.

6. Green-McKenzie J, Shofer FS (2006) Duration of time on shift before accidental blood or body fluid exposure for housestaff, nurses and technicians. Infect Control Hosp Epidemiol 28: 5-9.

7. Knutsson A (2003) Health disorders of shift workers. Occup Med 53:103-108.

8. Niedhammer I, Lert F, Marne MJ (1996) Prevalence of overweight and weight gain in relation to night work in a nurses' cohort. Int J Obes Relat Metab Disord 20: 625-33.

9. Karlsson B, Knutsson A, Lindahl B (2001) Is there an association between shift work and having a metabolic syndrome? Results from a population based study of 27,485 people. Occup Environ Med 58: 747-52.

10. Parkes KR (2002) Shift work and age as interactive predictors of body mass index among offshore workers. Scand J Work Environ Health 28: 64-71.

11. Chee HL, Kandiah M, Khalid M, Shamsuddin K, Jamaluddin J, et al. (2004) Body mass index and factors related to overweight among women workers in electronic factories in Peninsular Malaysia. Asia Pac J Clin Nutr 13: 248-254.

12. van Drongelen A, Boot CR, Merkus SL, Smid T, van der Beek AJ (2011) The effects of shift work on body weight change-a systematic review of longitudinal studies. Scand J Work Environ Health 37: 263-75.

13. Di Lorenzo L, De Pergola G, Zocchetti C, L'Abbate N, Basso A, et al. (2003) Effect of shift work on body mass index: results of a study performed in 319 glucose-tolerant men working in a Southern Italian industry. Int J Obes Relat Metab Disord 27: 1353-1358.

14. Suwazono Y1, Dochi M, Sakata K, Okubo Y, Oishi M, et al. (2008) A longitudinal study on the effect of shift work on weight gain in male Japanese workers. Obesity (Silver Spring) 16: 1887-1893.

15. Macagnan J, Pattussi MP, Canuto R, Henn RL, Fassa AG, et al. (2012) Impact of nightshift work on overweight and abdominal obesity among workers of a poultry processing plant in southern Brazil. Chronobiol Int 29: 336-43.

16. Buss J1 (2012) Associations between obesity and stress and shift work among nurses. Workplace Health Saf 60: 453-458.

17. Kennedy G, Ballard T, Dop MC (2013) Guidelines for measuring household and individual dietary diversity. Rome: Nutrition and consumer protection division. Food and agriculture organization.

18. Kant AK, Block G, Schatzkin A, Ziegler RG, Nestle M (1991) Dietary diversity in the US population, NHANES II, 1976-1980. J Am Diet Assoc 91: 1526-1531.

19. USDA's food guide pyramid (1996) Washington: US Department of Agriculture. 
Citation: Mirzaei K (2018) The Association between Dietary Diversity with Shift Work among the Nurses. J Nurs Care 7: 461. doi: $10.4172 / 2167-1168.1000461$

Page 8 of 8

20. Mirmiran M AL, Azizi F (2005) Is there any association between dietary diversity score and cardiovascular risks in Tehranian adults? Iran J Endocrinol Metab 7:189-98.

21. Azadbakht L, Zarifab F, Haghighatdoost F, Esmaillzadeh A (2010) Association of dietary diversity score with obesity and central adiposity among female university students in Isfahan, Iran. Iran J Nutr Sci Food Technol 5: 27-34.

22. McCrory MA, Fuss PJ, McCallum JE, Yao M, Vinken AG, et al. (1999) Dietary variety within food groups: association with energy intake and body fatness in men and women. Am J Clin Nutr 69: 440-447.

23. Jayawardena R, Byrne NM, Soares MJ, Katulanda P, Yadav B, et al. (2013) High dietary diversity is associated with obesity in Sri Lankan adults: an evaluation of three dietary scores. BMC Public Health 13: 314.

24. Rolls BJ, Rowe EA, Rolls ET (1982) How sensory properties of foods affect human feeding behavior. Physiol Behav 29: 409-17.

25. Raynor HA, Epstein LH (2001) Dietary variety, energy regulation, and obesity. Psychol Bull 127: 325-341.

26. Torheim LE, Ouattara F, Diarra MM, Thiam FD, Barikmo I, et al. (2004) Nutrient adequacy and dietary diversity in rural Mali: association and determinants. Eur J Clin Nutr 58: 594-604.

27. Mirmiran P, Azadbakht L, Azizi F (2005) Within Food Group Variety: An Indicator of Nutrient Adequacy in Tehrani Women. Razi J Med Sci 12: 155-65.

28. de Assis MA, Kupek E, Nahas MV, Bellisle F (2003) Food intake and circadian rhythms in shift workers with a high workload. Appetite 40: 175-183.

29. Faugier J, Lancaster J, Pickles D, Dobson K (2001) Barriers to healthy eating in the nursing profession: Part 1. Nurs Stand 15: 33-36.

30. Faugier J, Lancaster J, Pickles D, Dobson K (2001) Barriers to healthy eating in the nursing profession: Part 2. Nursing Standard (RCNP) 15: 33-35.

31. Ishizaki M, Morikawa Y, Nakagawa H, Honda R, Kawakami N, et al. (2004) The influence of work characteristics on body mass index and waist to hip ratio in Japanese employees. Ind Health 42: 41-49.

32. Kim MJ, Son KH, Park HY, Choi DJ, Yoon CH, et al. (2013) Association between shift work and obesity among female nurses: Korean Nurses' Survey. BMC Public Health 13: 12-4.

33. Han K, Trinkoff AM, Storr CL, Geiger-Brown J (2011) Job stress and work schedules in relation to nurse obesity. J Nurs Adm 41: 488-495.

34. Zhao I, Bogossian F, Song S, Turner C (2011) The association between shift work and unhealthy weight: a cross-sectional analysis from the Nurses and Midwives' e-cohort Study. J Occup Environ Med 53: 153-158.
35. Zhao I, Bogossian F, Turner C (2012) A cross-sectional analysis of the association between night-only or rotating shift work and overweight/ obesity among female nurses and midwives. J Occup Environ Med 54: 834-840.

36. Griep RH, Bastos LS, Fonseca Mde J, Silva-Costa A, Portela LF, et al. (2014) Years worked at night and body mass index among registered nurses from eighteen public hospitals in Rio de Janeiro, Brazil. BMC Health Serv Res 14: 603.

37. Escribà V, Pérez-Hoyos S, Bolumar F (1992) Shiftwork: its impact on the length and quality of sleep among nurses of the Valencian region in Spain. Int Arch Occup Environ Health 64: 125-129.

38. Sudo N, Ohtsuka R (2001) Nutrient intake among female shift workers in a computer factory in Japan. Int J Food Sci Nutr 52: 367-378.

39. Cho E, Sloane DM, Kim EY, Kim S, Choi M, et al. (2015) Effects of nurse staffing, work environments, and education on patient mortality: an observational study. Int J Nurs Stud 52: 535-542.

40. TT (2008) Working conditions and health. Soc Epidemiol 95-117.

41. AS P (2011) ICU nurses' job stress, health promoting behavior, and health status. Unpublished master's thesis Seoul, Korea: Yonsei University.

42. Persson M, Mårtensson J (2006) Situations influencing habits in diet and exercise among nurses working night shift. J Nurs Manag14: 414-23.

43. Trinkoff A, Geiger-Brown J, Brady B, Lipscomb J, Muntaner C (2006) How long and how much are nurses now working? Am J Nurs 106: 60-71.

44. Ahmadi A, Torkamani P, Sohrabi Z, Ghahremani F (2013) Nutrition knowledge: application and perception of food labels among women. Pak J Biol Sci 16: 2026-2030.

45. Magarey AM, Pettman TL, Wilson A, Mastersson N (2013) Changes in primary school children's behaviour, knowledge, attitudes, and environments related to nutrition and physical activity. Int Sch Res Notices Obes 19: 752081.

46. Ciccone MM, Aquilino A, Cortese F, Scicchitano P, Sassara M, et al. (2010) Feasibility and effectiveness of a disease and care management model in the primary health care system for patients with heart failure and diabetes (Project Leonardo). Vasc Health Risk Manag 6: 297.

47. Scicchitano P, Cameli M, Maiello M, Modesti PA, Muiesan ML, et al. (2014) Nutraceuticals and dyslipidaemia: Beyond the common therapeutics. J Funct Foods 6:11-32. 